\section{Awareness of Coastal Disasters: Case of an Impoverished Low-Lying River Mouth Community in Southern Vietnam}

\author{
Miguel Esteban ${ }^{a^{*}}$, Hiroshi Takagi ${ }^{\mathrm{b}}$, Nguyen \\ Danh Thao ${ }^{c}$, Tran Thu Tam ${ }^{c}$, Doan Dinh Tuyet \\ Trang $^{\mathrm{c}}$, Le Tuan Anh ${ }^{\mathrm{b}}$, Ven Paolo Valenzuela
}

${ }^{a}$ Graduate Program in Sustainability Science, Global Leadership Initiative (GPSS-GLI), The University of Tokyo, Tokyo, Japan

${ }^{b}$ Tokyo Institute of Technology, Tokyo, Japan

${ }^{c}$ Ho Chi Minh City University of Technology, Vietnam

Received: May 2, 2017 / Accepted: December 4, 2017

\begin{abstract}
Impoverished communities often suffer disproportionately due to natural hazards, as their inhabitants live in lands which are particularly prone to natural hazards, and exhibit lower levels of awareness and preparedness than other communities. In the present research the authors conducted structured questionnaire surveys amongst a poor community living on top of discarded sea shells in a river bank in Phan Thiet in Southern Vietnam in order to understand the level of awareness of residents against coastal hazard. The results show that although local inhabitants appear to have a moderate to high level of awareness about flooding and typhoon hazards, the evaluation of the risk that they pose to them is moderate to low. Despite the low frequency of coastal hazards in the area, the consequences of any significant event would be disastrous, as the community is located less than half a metre above water level. Thus, it is imperative that better countermeasures are put in place in the area to improve the resilience of inhabitants and ensure the long-term sustainability of the settlement.
\end{abstract}

Keywords: Coastal hazard; Coastal disaster; Vietnam; Coastal erosion; Tourism; Sea-level rise

\section{Introduction}

Vietnam is one of the most vulnerable countries against coastal hazards, especially storm surges caused by tropical cyclones (TC). A storm surge is an increase in sea water levels brought about by high winds pushing on the ocean's surface, combined with the effect of low pressure at the centre of the typhoon. Despite a number of prominent events in the past decade, few people inside or outside of Vietnam realize the true vulnerability of the country against natural hazards, be it due to typhoons or the possibility of a distant source tsunami reaching the country. There are multiple reasons behind this relative lack of awareness to coastal hazards in Vietnam. Basically, since typhoon Linda killed over 3,0oo people in 1997, no extreme coastal disasters have affected the country [1, 2]. This contrasts to neighbouring countries, which have recently experienced several large disasters exceeding 5,00o casualties, contributing to raising awareness. This includes for example the 2004 Indian Ocean Tsunami [3], the 2008 Cyclone Nargis in Myanmar [4], the 2009 and 2010 tsunamis in Samoa and Mentawai [5-7], the 2011 Tohoku Earthquake Tsunami [8,9], and the 2013 Typhoon Haiyan in the Philippines [10,11].

Awareness about disasters is not constant, and will typically vary amongst a given population throughout time, with recent events reinforcing awareness, and then this awareness gradually fading with time unless appropriate efforts in education and training are made. This idea was conceptualized by Esteban et al. [7], who explained how a given event (in a country that has not experienced a given type of disaster for several generations) can very rapidly raise awareness. This awareness would gradually decay as the subsequent generations and immigrants from other areas slowly replaced those who witnessed the event, though some degree of awareness might persist in the form of stories told from one generation to the next. Eventually, all memory of the event would fade unless significant efforts are made in education and training or the construction of tsunami or flooding memorials, which can succeed in preserving a high state of awareness, similar to that present in those affected in Japan in 2011 [12-14].

Many researchers have identified how typhoons pose a great threat to Vietnam [2, 15-17]. In particular, the northern coast is hit by typhoons more frequently than any other part of the country [16]. The maximum storm surge offshore the Red River Delta during a typhoon can be 1 to $1.5 \mathrm{~m}$ above mean sea level (MSL), but as the surge progresses towards the coast it typically grows higher [18] The possibility of a large typhoon taking place in southern Vietnam is considerably smaller than in the northern and central parts of the country [1]. However, this does not necessarily mean that southern Vietnam is less vulnerable against typhoons. Numerical simulations for several selected tropical cyclones in the past show that storm surges as high as $1 \mathrm{~m}$ took place along coastal areas in Southern Vietnam [1]. Although these authors show that the number of TCs that have made landfall along the coasts of the southern part of Vietnam is about one fourth of those which approach the northern and central parts, these could still cause severe damage to houses in a low-lying riverbank or severely eroded coasts through high winds, storm surge and waves. The damage to these areas would probably far exceed that caused by TCs to other parts of the country, due to the lack of preparedness of coastal communities in southern Vietnam, where local inhabitants are typically ignorant of the effects of TCs.

The possibility that a tsunami could affect the Vietnamese coast is not high [19]. Thao [20] analysed 25 scenarios for tsunami generation prepared by Ministry of Natural Resources and Environment, and then the five most dangerous scenarios were 
selected to simulate the tsunami propagation in the East Sea of Vietnam. The results show that after an earthquake takes place in the western coast of Luzon Island (in the Philippines), a tsunami would reach the middle part of the Vietnamese coast approximately 90 minutes later, and would then gradually propagate to the northern and southern coasts of the country. The tsunami height would reach a maximum height of between $1 \mathrm{~m}$ and $5 \mathrm{~m}$, especially for the potentially most hazardous earthquake scenarios at the Manila Trench. Work by other researchers arrive at similar conclusions [19, 21-23].

However, it is not clear how aware are local communities in Vietnam, and particularly impoverished communities, regarding the risks posed by tsunamis and storm surges. In fact, it is interesting to note how awareness about tsunamis has become so widespread that it appears higher than that for other types of flooding such as storm surges. This seems to also be the case for other countries around the world. For example, in the case of typhoon Haiyan in 2013, one of the strongest typhoons in recent times $[10,11]$, it appeared that local residents had a low level of awareness about the nature of storm surges [24]. Many residents seemed not to understand the concept of storm surge, with a number of individual expressing how it would have been better for authorities to describe it as a "tsunami [13, 14].

The awareness of local residents about natural hazards is clearly location specific, and depends on a number of factors such as culture, education, and the policies of local and national governments. The degree of awareness and preparedness can be reflected by a variety of factors, according to the protection measures implemented, the willingness to evacuate, and the various measures taken by authorities or individuals [7]. Particularly, studies on evacuation behaviour and awareness can provide good insights into awareness about coastal hazards, though such studies have typically focused on tropical cyclone evacuation [25] and evacuation intent. For example, in the United States studies have investigated the intended or hypothetical evacuation behaviour from hurricanes [26], typically also complemented by research on the willingness to evacuate of specific groups (such as older adults, [27]). Fraser et al., [28] studied the intended evacuation behaviour against a tsunami of residents and visitors to Napier City in New Zealand. Matsumaru and Kawaguchi [29] studied the awareness on tsunami disasters to visitors at the tourist site of Enoshima, south of Tokyo city in Japan (with other studies targeting nearby cities [30-31]. Other surveys on knowledge, attitude and Practice (KAP) have been carried out in in Trinidad and Tobago [32], Vietnam [33] (Esteban et al., 2014) or after disasters already took place $[7,34,35]$. Generally speaking, all those studies paint a picture of increased awareness throughout the world, as exposure to disasters in other countries result in many individuals having some degree of understanding of the nature of disasters. However, significant cultural and local factors play a role in the extent of awareness and knowledge about how to evacuate, and thus require further study.

Through their field trips over the last 10 years (See Fig. 1) the authors identified that the small fishery community of Phu Trinh in Phan Thiet city could be especially vulnerable to tropical cyclones, storm surges and even a low height tsunami. This settlement is located on the banks of the Ca Ty River, built on top of land which was reclaimed using oyster shells and other waste (See Figures 1 and 2). Although it is one of the lowest points in the city, only situated around $49 \mathrm{~cm}$ above Mean Sea Level according to the authors' surveys, most of the surrounding neighbourhoods of Phan Thiet are also situated in low-lying areas. Nevertheless, Phu Trinh is considerably lower than the rest of the city, so it is sometimes inundated during the rainy season.
Takagi et al. [1] estimated that a storm surge as high as $1 \mathrm{~m}$ occurred in Phan Thiet in 1962 during the passage of typhoon Lucy. Although a one-meter storm surge is not as large as those that take place in the northern and central parts of Vietnam, the special socio-economic and cultural characteristics of this local community are likely to be different to those in northern Vietnam. The population in the area in 1962 was limited, and hence it is probable that the losses would also have been limited. Also, it is likely that less people lived in Phu Trinh at the time, and hence there is no cultural memory of the effects of the passage of the typhoon in this area of the town. Although the residents are to some extent accustomed to river flooding, and are thus used to "getting their feet wet" and "living with water", they seem to be unaware that tropical storms can bring about a violent storm surge, as they have had no experience of storm surges in the past few decades. Also, it is possible that future changes in hydrology could make normal river floods more frequent, and there is evidence there are already changes in water regimes in other countries [36].

Thus, if a tropical cyclone of the same level as Lucy hits an extremely low-lying area such as Phu Trinh, it will probably cause severe damage through the high winds, storm surge and waves. Since this area of the city is located only $1.5 \mathrm{~km}$ upstream of the river mouth, the storm surge due to a large typhoon or a small tsunami would quickly progress up the river, damage houses and carry with it any residents that did not evacuate. It should be noted also that the inhabitants of this area are generally poor, and that the quality of construction of the houses is rather low, so that the occurrence of a storm surge lead to widespread devastation. It is also obvious that damage to these communities in the future will become larger, when the effects of sea-level rise and climate change start to be felt more acutely.

The purpose of the present research is thus to establish the level of awareness about tsunamis and storm surges present amongst the community, and attempt to outline some potential measures that could improve their preparedness against such events. Such research is particularly important given that the area is one of the most impoverished in the city, and the link between resilience and inequality, and resilience to infrastructure is one that has received comparative little attention in the past [37].

Establishing such links is also particularly important within the scope of the most recent global disaster risk reduction framework the Sendai Framework for Disaster Risk Reduction 2015-2030. The framework's goal is to "prevent new and reduce existing disaster risk through the implementation of integrated and inclusive economic, structural, legal, social, health, cultural, educational, environmental, technological, political and institutional measures that prevent and reduce hazard exposure and vulnerability to disaster, increase preparedness for response and recovery, and thus strengthen resilience" [38]. The framework promotes that societies should understand their risks and then plan and act accordingly, in order to absorb known and unknown shocks and disturbances.

The framework has four priorities for action: 1) Understanding disaster risk, 2) Strengthening disaster risk governance to manage disaster risk, 3) Investing in disaster risk reduction for resilience, and 4) Enhancing disaster preparedness for effective response and to "Build Back Better" in recovery, rehabilitation, and reconstruction [38]. All four priorities are to be implemented at the local, national, and global scales, with emphasis on promoting long-term resilience towards disasters.

Improving resilience to natural disasters is of paramount important to ensure the long term sustainability of coastal settlements. Thus, much research and attention within the field of sustainability science has been placed on the concept of resilience, and how can human socio-economic systems be improved in order to make them less prone to failure during extreme events. The 
present work inscribes itself within this long-term trend, by attempting to look at the problem from a holistic and transdisciplinary perspective. Essentially, field surveys by coastal engineers were complemented through questionnaire surveys that are more typical of the social sciences, attempting to understand the awareness of coastal communities against natural disasters. Understanding this can then help to create effective risk reduction and mitigation strategies, which will hopefully lead to an increase in resilience.

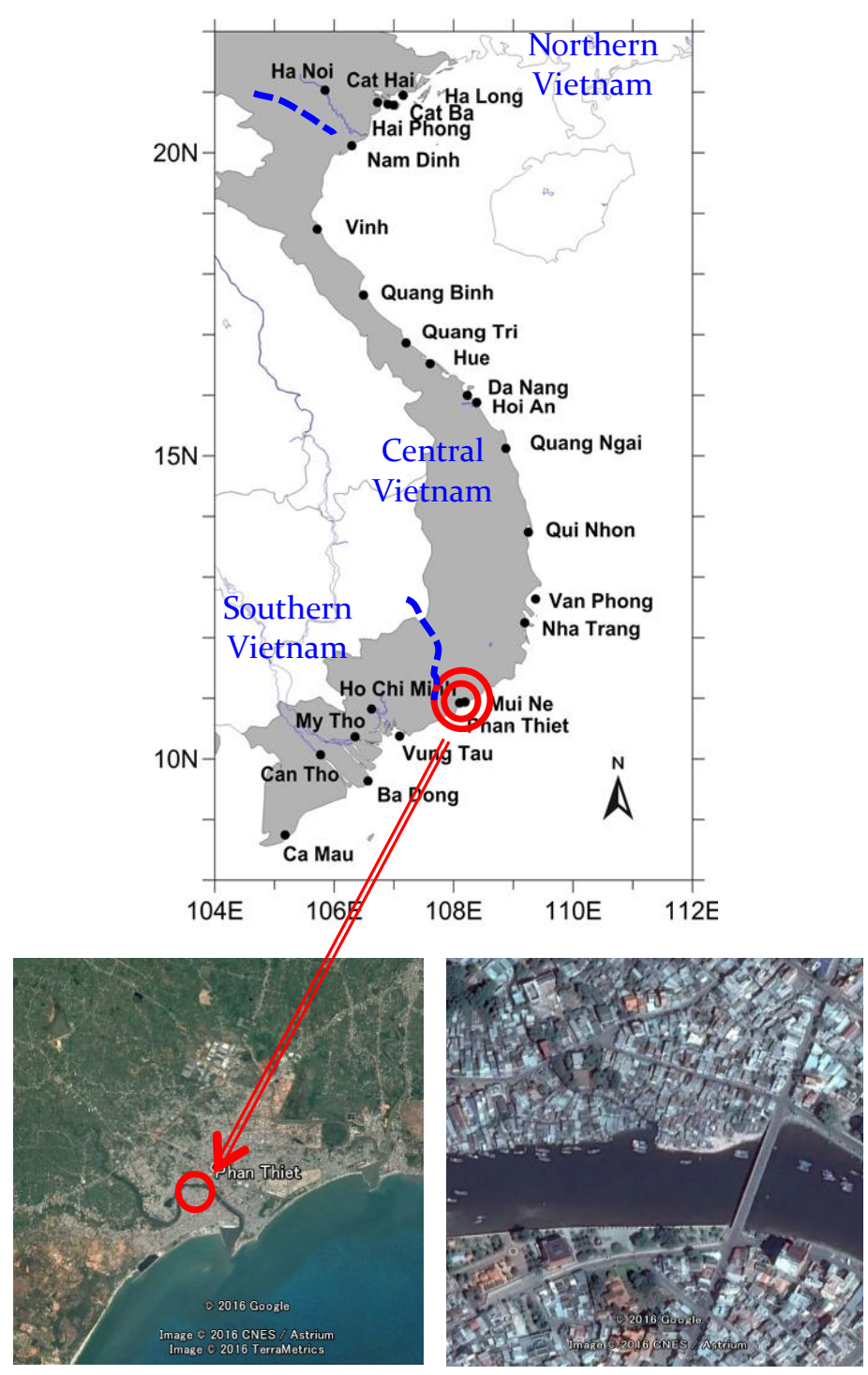

Figure 1 Top: Map of Vietnam, showing the location of Phan Thiet. Bottom left: Map of Phan Thiet, showing location of Phu Trinh. Bottom right: Phu Trinh

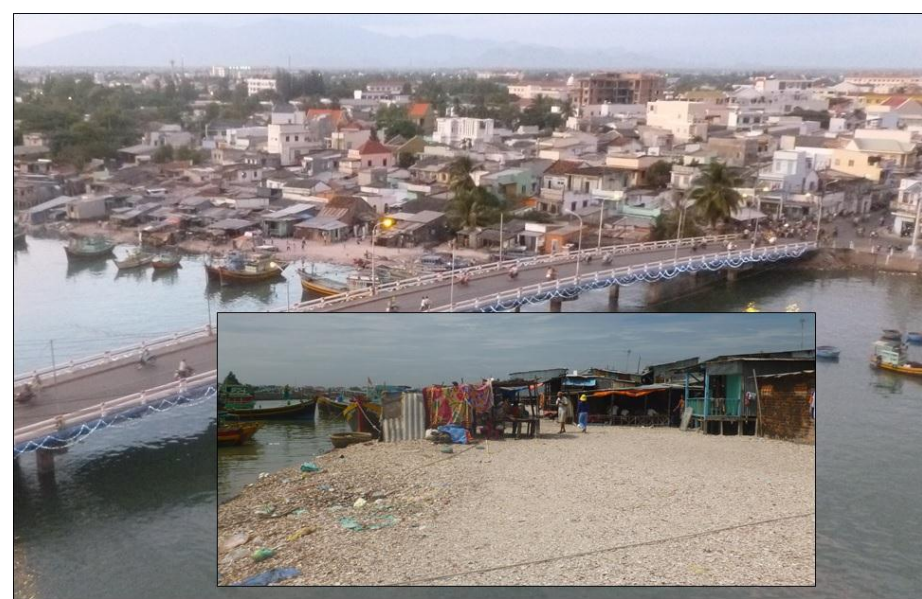

Figure 2 View of Phu Trinh. Photos taken in January 2012.

\section{Methodology}

A structured questionnaire survey was conducted amongst the inhabitants of the small fishing community in Quarter 8 of Phu Trinh Ward, which sits on the margins of the Ca Ty river in the city of Phan Thiet, in Vietnam. Coastal fishing, particularly for clam and oyster production, is conducted by local fishermen in shallow waters not far away from the shoreline, normally from early morning to mid-afternoon. While the men are out at sea fishing, women are in charge of selling the products to the local market. The authors administered the questionnaire directly by walking around the narrow streets of the community in February 2017 until the number of people available for interview was exhausted, see Figure 3 (i.e. all adults present were approached, though some people were either too busy or chose not to answer the questionnaire). As a result, a total of 86 valid responses $(n=86)$ were collected amongst adults in the area (aged 18+, children and teenagers were excluded from the survey). Despite the relatively small sample size, the results were considered to be significant given the small population size in the area. The authors counted 140 houses using a Google Earth satellite image (maybe around 600 people in total, if each family is composed of 4-5 members ${ }^{*}$ ), and thus the present work would represent around $21 \%$ of households. Chi-square tests were performed on the data, though no significant trends could be found (probably due to the relative homogeneous nature of the sample).

The questionnaire covered a number of different topics, including whether the respondents' house was in danger of being flooded from the sea or rivers, if they had experienced some sort of damage from a previous disaster (and in that case, what was the extent of the damage), if they had joined evacuation drills in the last 5 years, if they knew whether there was a tsunami warning system in the area, whether children learn about storm surge/tsunami hazards at school, and their sources of information regarding natural hazards. Regarding specific threats, the

* Ascertaining the exact number of residents in the area is a very difficult task. It is an informal settlement and the number of residents recorded by the local authorities is probably incorrect, as most people living there are probably not registered as permanent residents in that area or at all. It should be noted that there is a variety of different types of residence in Vietnam, including those that have "permanent residency registration" ("hộ khẩu thường trú"), those under $\mathrm{KT}_{3}$ status (long-term residency for nonlocals of the province), short term residents, people who might be registered in an area different to the one they live in, and even people who might have not be registered at all. 
questionnaire also asked whether respondents knew what a typhoons storm surge and tsunami were, if they thought that this represented a read danger to them, and whether they knew how to evacuate against each type of hazard. Finally, demographic information was also collected from respondents. The questionnaire survey was originally drafted in English and then translated into Vietnamese, with all enumerators being native Vietnamese speakers. Despite to the opportunistic nature of the survey and the fact that the authors attempted to exhaust all available potential candidate respondents in the area, an almost balanced sample was obtained, with $48 \%$ of respondents describing themselves as males and $51 \%$ as females (one respondent would rather not answer that question). Figure 4 shows how respondents were predominantly young, with $69 \%$ being under the age of 40 , which could be considered typical in a country with a young population such as the Vietnam [33]. As could be expected from the age distribution and the socio-economic characteristics of the area (see Figure 5), most adults were employed in the fishing industry (21\%, see Figure 6), with many of the young defining themselves as students (17\% of respondents). Figure 6 shows how domestic workers, housewives and office workers constituted other major groups $(6 \%, 19 \%, 14 \%$, respectively), though it is worth noting that some of the older respondents were retired $(5 \%)$ and some described themselves as not having a job (3\%). Most adults were married ( $63 \%$ of all respondents) and almost all of them (97\%) said that they were living with their families (as opposed to with friends or alone), something that could be considered typical in presentday Vietnamese society.

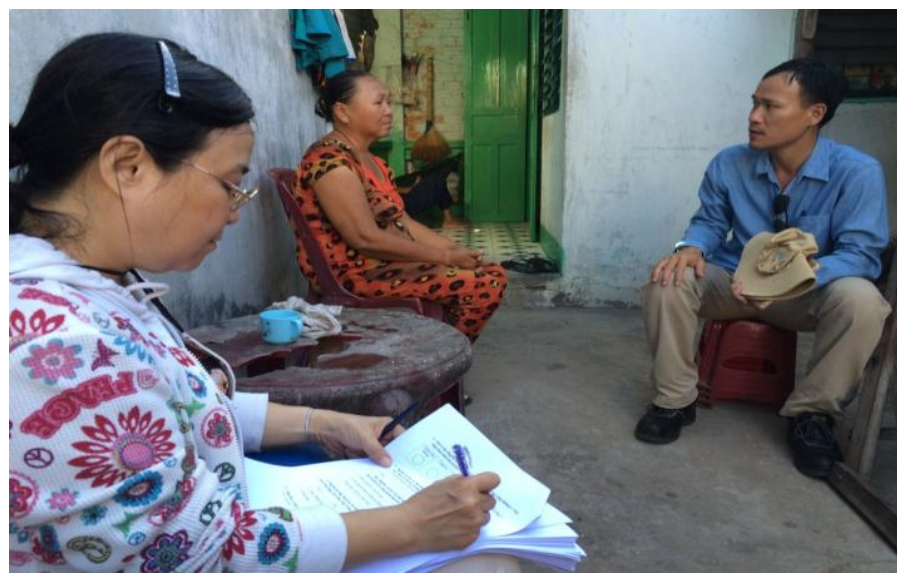

Figure 3 Structured questionnaire surveys were administered by the authors amongst local residents.

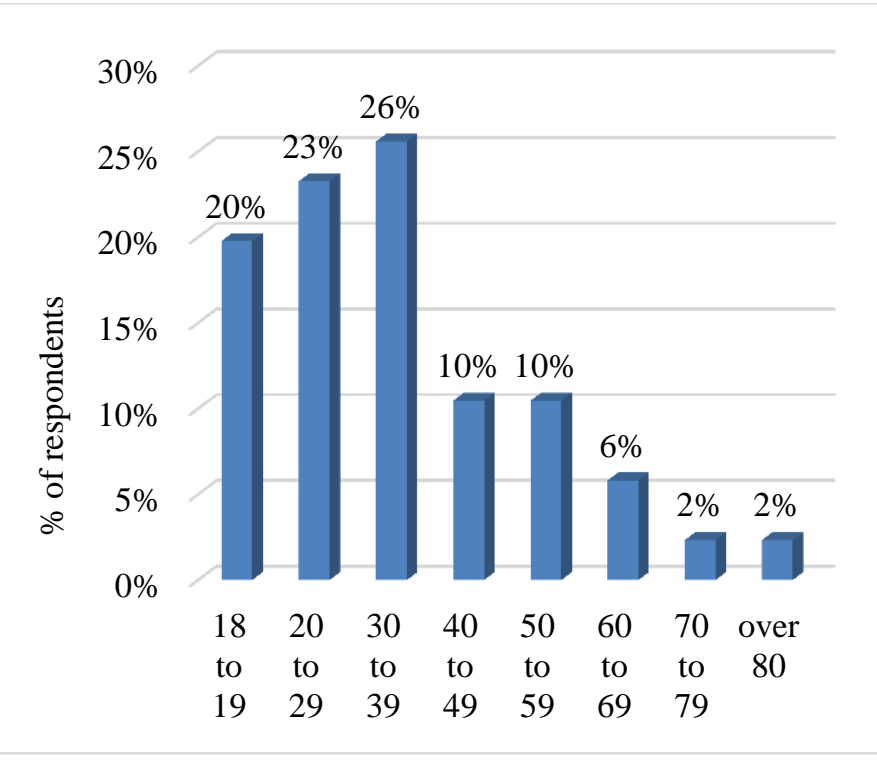

Figure 4 Age distribution of respondents $(\mathrm{n}=86)$

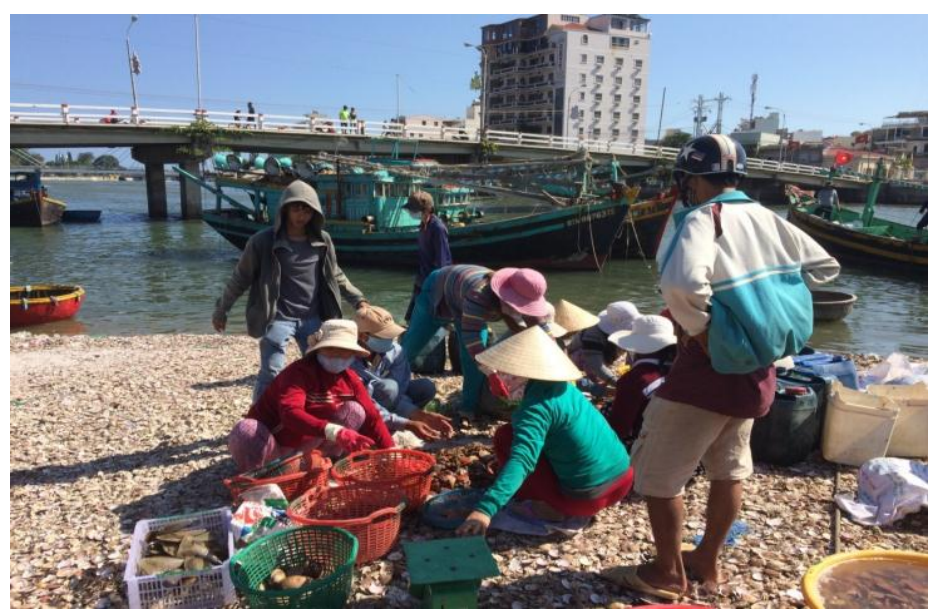

Figure 5 Typical view of economic activities in this settlement. Fishing boats operated by males bring fish and different types of shellfish, which are sorted by females on the banks of the river, essentially made up of an accumulation of discarded shells. Through a survey carried out by the authors the area was measured to be $49 \mathrm{~cm}$ above the mean sea level. 


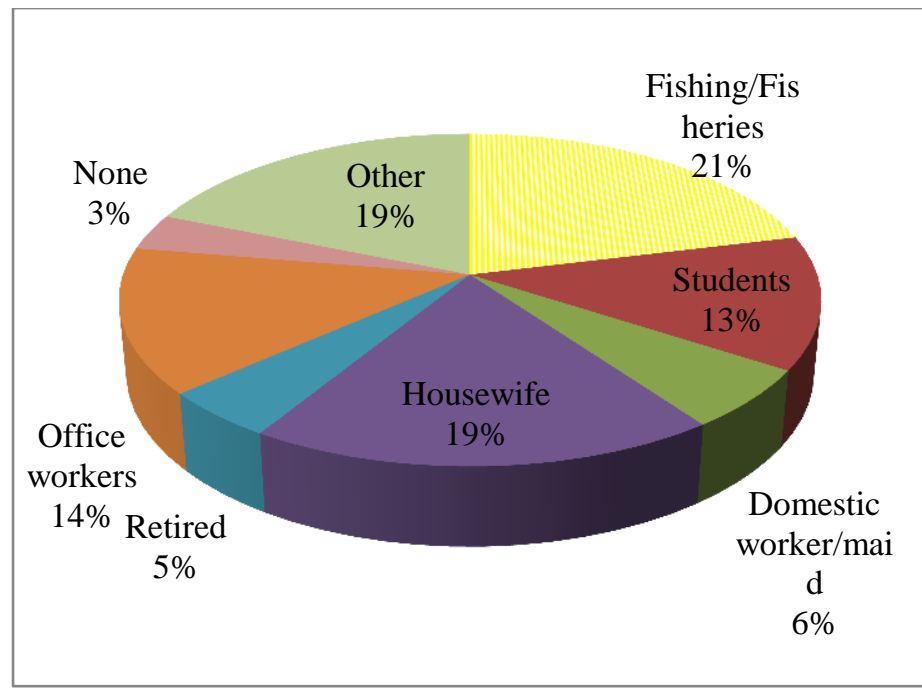

Figure 6 Occupation of respondents $(\mathrm{n}=86)$

\section{Results}

One third of respondents (37\%) answered that they thought their house was at least moderately in danger of suffering from coastal or river flooding (on a 5 point Likert scale, as shown in Figure 7). This correlated reasonably well with the number of respondents who have suffered from coastal flooding in the past, with $50 \% \quad(n=43)$ indicating that they had suffered some sort of damage. Of these, $70 \%$ said that they had suffered only minor damage, and the rest major damage, though none reported that their houses had been totally destroyed (see Figure 8)

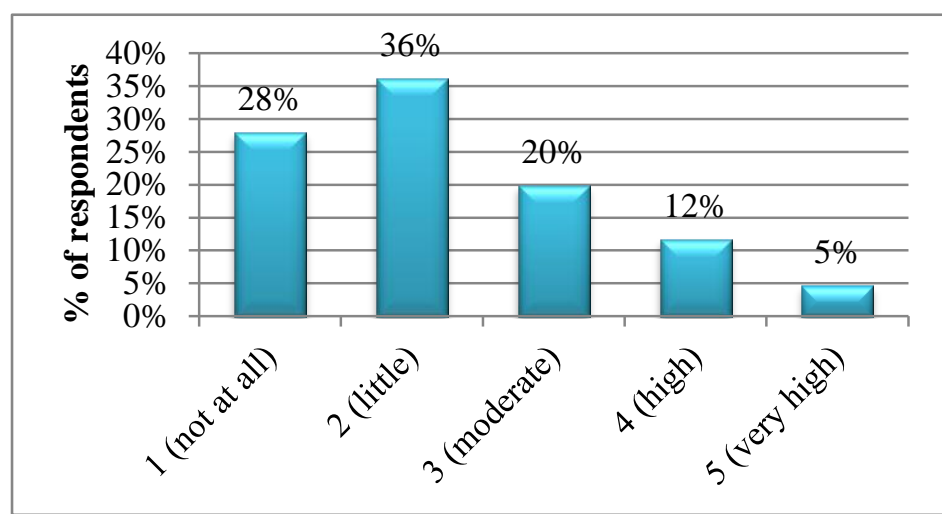

Figure 7 Distribution of the opinion of respondents regarding whether they thought their house is at danger of flooding from the sea or rivers $(n=86)$

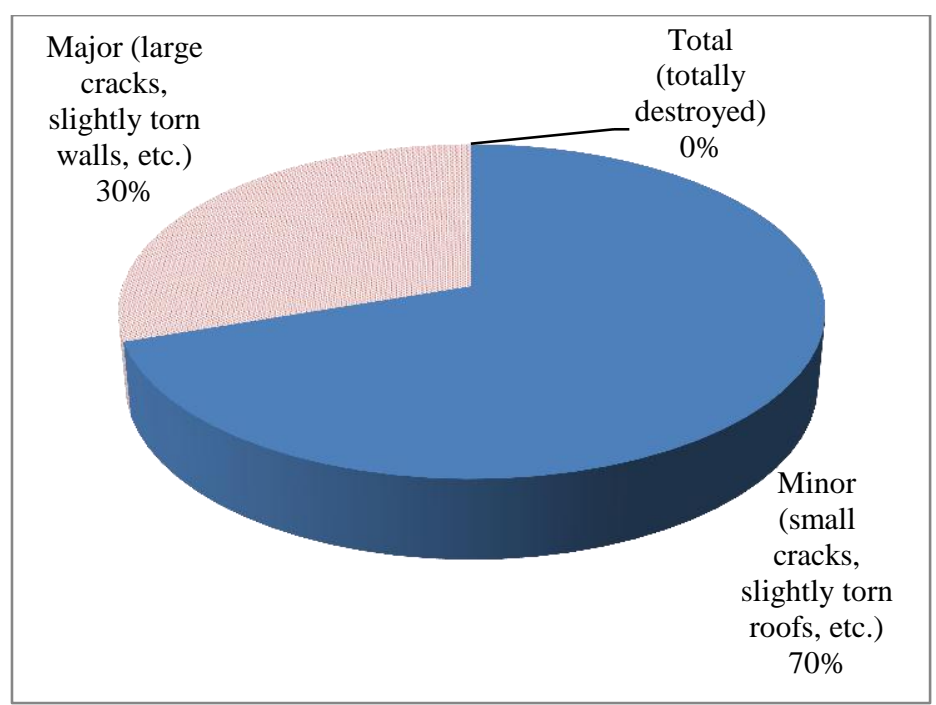

Figure 8 Distribution of the type of damage that respondents said they had suffered from a previous disaster $(n=43)$

In terms of awareness, $72 \%$ of respondents indicated that they knew what a storm surge was, though only $40 \%$ thought that these posed a high or very high danger to them (jumping to over half $(56 \%)$ if the "moderate" danger was included, see Figure 9). In line with this answer, their interest in evacuation was not so high, though $63 \%$ of respondents indicated that they knew how to evacuate in the event of a storm surge.

Regarding tsunamis, the number of respondents who were aware about the nature of these phenomena was lower (only $63 \%$ of respondents knew), and $56 \%$ thought that it could represent a high or very high danger to them (which jumped to $79 \%$ of respondents if the "moderate" danger is included, see Figure 10). Only $31 \%$ indicated that they knew how to evacuate in such an event. Nevertheless, the fact that any awareness exists is rather remarkable, considering how there has been no tsunami in recent times in Vietnam [20,33]. This awareness is arguably the result of recent events in other countries, such as Japan and Indonesia [7].

Regarding tsunami preparedness, only a minority of respondents $(36 \%)$ had taken part in evacuation drills in the last 5 years (see Figure 11). In terms of where their knowledge about natural hazard came from, Figure 12 shows that most of them obtained information from the TV or radio (66\%), public address systems $(64 \%$, which included loudspeakers or cars with loudspeakers), or authority figures ( $47 \%$, including village leaders, policemen, firefighters). It is interesting to note how in at least some schools children learn about storm surge/tsunami hazards, and how evacuation should be conducted (about 31\% confirmed that this was indeed the case, though half of respondents did not know whether such education activities were carried out or not). 


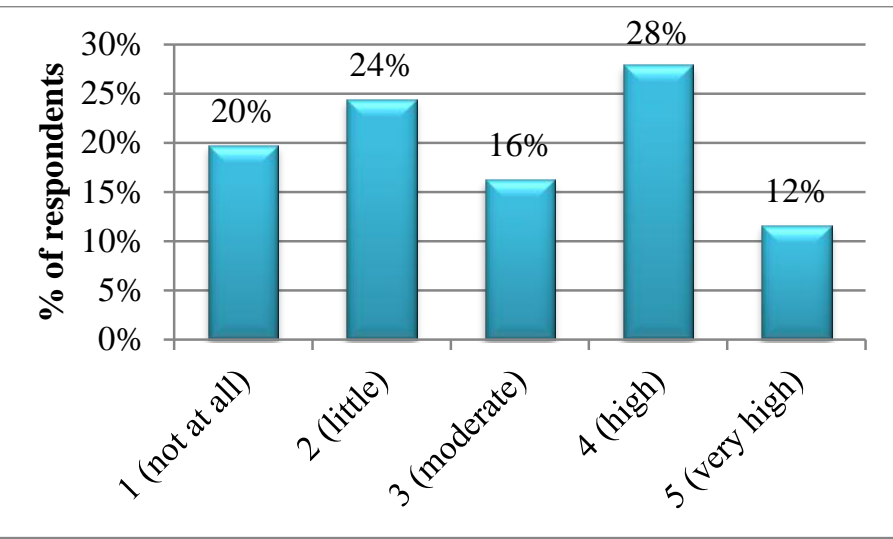

Figure 9 Distribution of respondents who think that a storm surge constitutes a real danger for them. An answer of 1 (not at all) indicates they thought they were not at all in danger, were 5 (very high) indicates the respondent thought such an event constituted a very real danger to them $(n=86)$

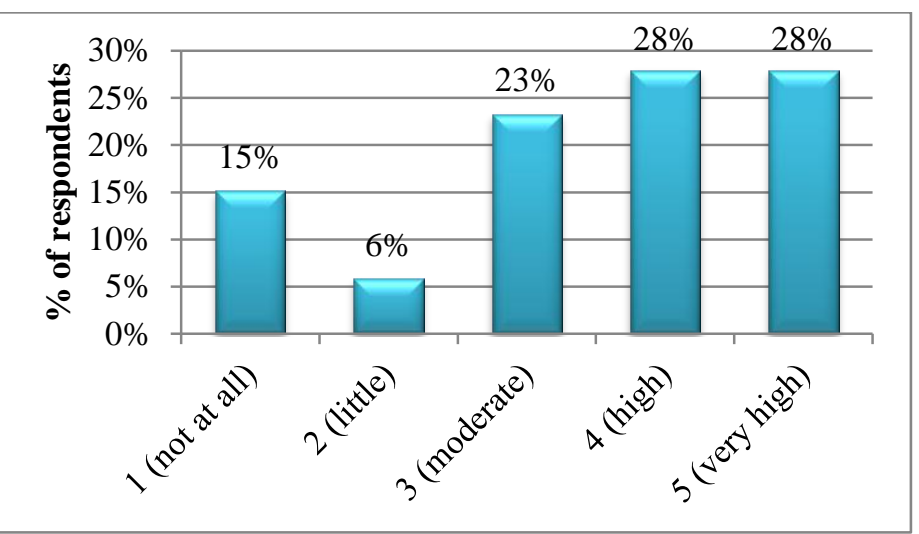

Figure 10 Distribution of respondents who thought a tsunami constitutes a real danger for them. An answer of 1 (not at all) indicates they thought they were not at all in danger, were 5 (very strongly) indicates the respondent thought such an event constituted a very real danger to them $(n=86)$

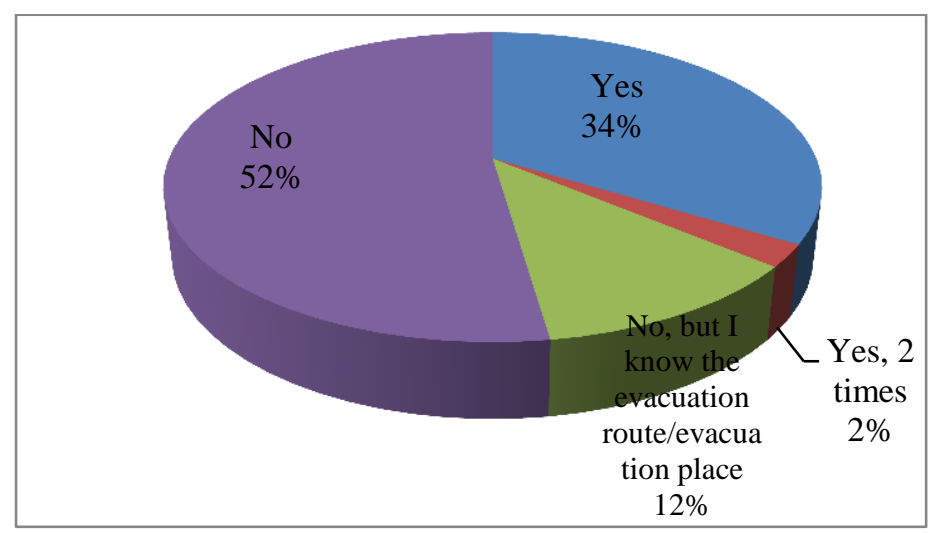

Figure 11 Distribution of respondents regarding whether they had taken part in evacuation drills in the last 5 years $(n=86)$

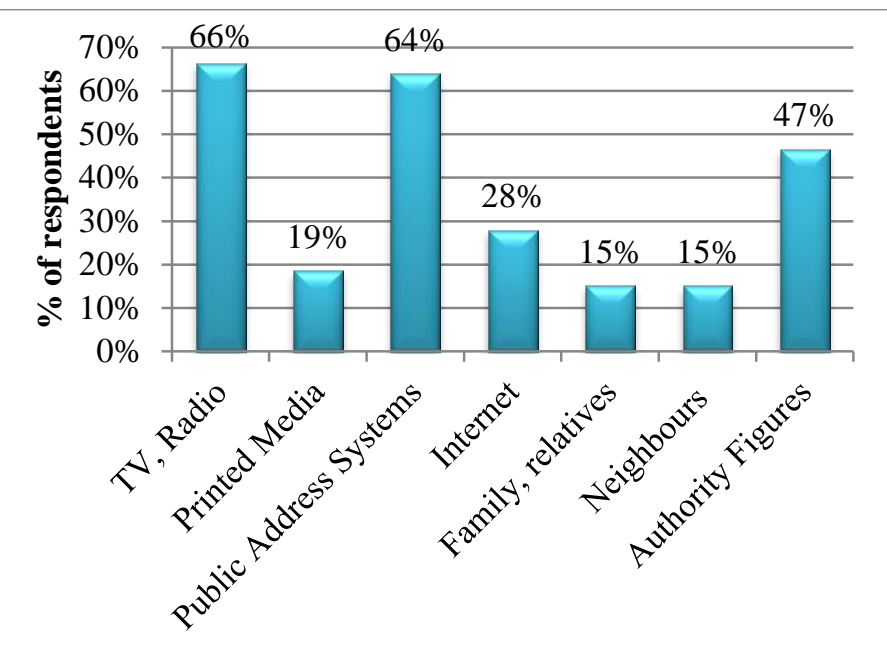

Figure 12 Source of information on storm surge and typhoon (multiplechoice allowed). Printed media includes newspapers, pamphlets and other brochures. Authority figures include village leaders, police or firefighters $(n=86)$

\section{Discussion}

It is well known that impoverished communities often suffer the most from natural disasters, as proven for example during the storm surge in Tacloban city during typhoon Haiyan in 2013 [13, 14, 24] or other recent disasters [7]. During the field surveys carried out by the authors it is clear that this community is particularly vulnerable to any type of flooding events, whether from the river, a storm surge due to a typhoon, or a tsunami. In fact, Figure 13 indicates how there is already a memorial pole in one of the river banks that is adjacent to the area of Phu Trinh. Any of the events indicated in this pole would result in the houses in Phu Trinh being flooded up to the roof level, as the area lies only a few centimetres above water level.

The results of the questionnaire show how the economy of this small settlement relies mostly on fishing, which accounted for around a quarter of all responses (though this rises to one third of responses when only considering those with jobs i.e. excluding students or house-wives, see Fig. 6). It should be noted that housewives often help with cleaning activities, as shown in Fig. 5, so the real proportion of the economy derived from fishing is likely to be much higher, possibly even up to half of the local economy). Fishing products appear to be sold to restaurants or directly to customers through informal stands on the side of the road next to the case study area (see Figure 14), emphasizing the precarious nature of the economy of the settlement.

Awareness about the level of threat posed by potentially dangerous flooding disasters does not seem to be particularly low. Although only $17 \%$ respondents thought that they were in high or very high danger of flooding from the sea or river, this figure climbs to over one third if the moderate category is included, see Figure 7 ). This can be partly explained by the relative youth of the population in the area (see Figure 4), that there has not been a major disaster for a rather long time (low frequency exposure, see Figure 13 and Table $i^{\dagger}$ ), and that few respondents had suffered any major damage due to any other previous disasters (Figure 8 ). It would seem that

\footnotetext{
${ }^{\dagger}$ Note the small discrepancy in flooding heights between the report and the table, probably because it was measured at different points along the river
} 
the area might be affected by frequent minor flooding (not surprising given that the settlement is only half a metre above the water levels close to the mouth of the river, which is less than $2 \mathrm{~km}$ away), and this might explain the relatively high levels of awareness about the danger of flooding. Respondents indicated that this flooding damaged the furniture or their houses, but the questionnaire was not able to capture whether respondents could really differentiate between coastal and river flooding.

The results show that, generally speaking, the local population has a high level of knowledge regarding the nature of storm surges (with $72 \%$ of respondents indicating that they knew what they were), and a slightly lower awareness about tsunamis (only 63\%). Such awareness can be attributed to frequent TV programs and weather forecasts being emitted in Vietnamese TV, especially after typhoon Haiyan in the Philippines in 2013. These results are somewhat similar to those found in previous studies (Esteban et al., [33], report how in a similar study in central Vietnam $76 \%$ of respondents indicated that they were aware of the danger of storm surges and $81 \%$ of tsunamis). Interestingly, despite this high level of awareness about the nature of storm surges, only $56 \%$ of respondents thought that it represented a moderate or high danger to them, compared for $79 \%$ for the case of tsunami. Quite a number of respondents thus thought a tsunami was more dangerous than a storm surge, despite stating that they did not clearly understand what it was. This represents a very peculiar find of this study, in that local residents seem to be more aware of the potential danger that a tsunami poses to them (despite not understanding properly what it is or how likely they are to suffer one), probably through exposure to media coverage of other events such as the 2011 Japan Earthquake Tsunami.

However, with regards to knowledge on how to evacuate significant differences could be found with previous studies. While $63 \%$ of respondents in the present study knew how to evacuate in the case of a storm surge (which compares well with the $70 \%$ in the study of Esteban et al. [33]), only 31\% knew how to evacuate against a tsunami ( $58 \%$ for the case of central Vietnam). Such differences can be explained by the fact that Vietnam has not experienced a tsunami disaster for a long time, possibly since the $19^{\text {th }}$ century, and how the most significant scenarios are unlikely to affect the study area (the worst scenarios are likely to relate to an earthquake in the Manila trench, which are unlikely to result in great inundation depths around Phan Thiet, and anyway there would likely be ample time to evacuate, see [20, 23]).

However, although the community would seem to have a relatively decent level of resilience against the kind of frequent flooding they have become accustomed to, they might be underestimating the dangers posed by a potential higher order event. Even relatively modest events could carry away the low-level wooden housing, possibly killing many people if it happened at night. Resilience is generally considered to have 3 components: agents (the people and organisations involved, including local authorities), institutions (referring to the sets of rules that guide human behaviour) and systems infrastructure. Also, modern disaster prevention systems should generally have multiple safety layers, ensuring that there are a variety of protection measures in place to protect both residents and property (National Water Plan of the Netherlands, 2012, Tsimopoulou et al., 2013). Typically, these consist of layer 1 "hard measures" (such as river levees), spatial planning (layer 2) and evacuation systems (layer 3). In this sense, the present case study represents a complete failure, as the settlement is located below the river wall (that can offer some protection to other houses, even though no proper river levees are present in Phan Thiet), and there are no warning and evacuation systems in place. One possibility to enhance resilience would be for local authorities to improve their emergency management, or build education and awareness through the most commonly accessed media (TV or local radios)

Discussions with local officials indicated that this community was formed spontaneously by fishermen and their families, without any prior planning from local government. In order to improve the riverbank's landscape and quality of life, as well as to raise the preparedness of local residents against natural disasters, there is an ongoing plan to construct a river dike along Ca Ty River, and all inhabitants will be relocated to a new safer resettlement. However, forced resettlement has many downsides, which can lead to impoverishment (at least at the start, Ong et al., 2016), and can be resisted by many residents (Jamero et al., 2016). While this idea of resettlement can be controversial, given the height of past flooding events (Figure 13) it is clearly only a question of time until the forces of nature overcome this wooden settlement.

At present local residents would have to rely almost entirely on evacuation (layer 3) in the case of a flooding event, though the success of this strategy would depend on whether residents actually evacuated or not. It is worth remembering how in other recent nearby storm surge events, such as that of typhoon Haiyan in the Philippines in 2013, many local residents did not evacuate, despite warning to do so. It seemed that many could not fully grasp the concept of a storm surge despite efforts from the authorities through announcements and the TV- to highlight the dangers and explain the phenomena (Esteban et al., 2015, Leelawat et al., 2014).

Table 1 Flooding events measured along Ca Ty River (Vietnam Ministry of Natural Resources and Environment, 2014)

\begin{tabular}{lll}
\hline Date & Water level & $\begin{array}{l}\text { Flooding reason } \\
\text { given }\end{array}$ \\
\hline October 1983 & $+1.7 \mathrm{~m}$ & $\begin{array}{l}\text { Heavy rain and } \\
\text { typhoon Kim }\end{array}$ \\
October 1993 & $+2.8 \mathrm{~m}$ & $\begin{array}{l}\text { Heavy rain } \\
\text { November } 2000\end{array}$ \\
\hline
\end{tabular}

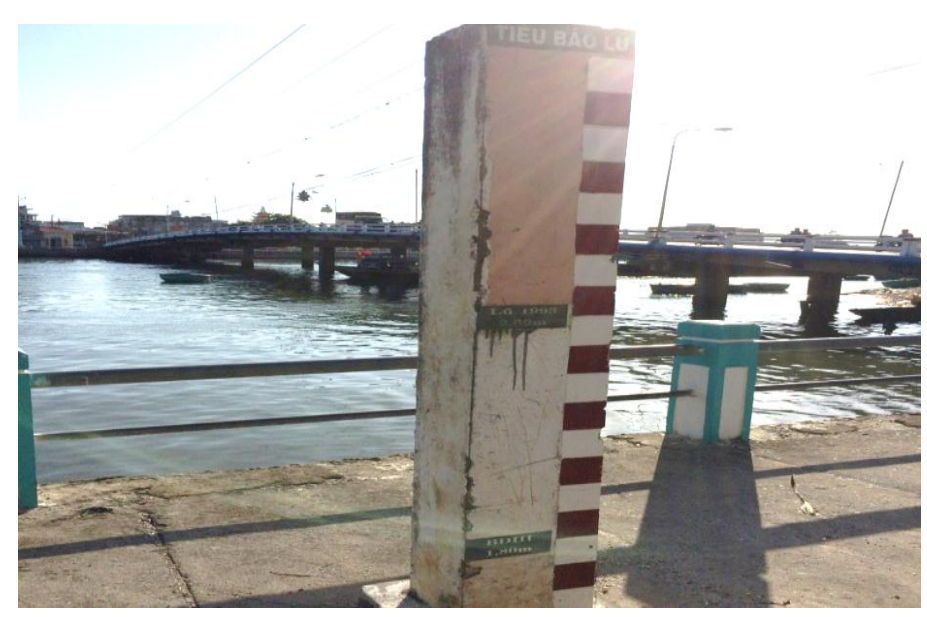

Figure 13 Memorial pole indicating the heights of previous river flooding events, including the historical river flood in 1993. The right hand side of the figure shows some small fishing boats and the edge of Phu Trinh, indicating how any of the flooding events marked on this pole would flood the houses in the area, almost to roof level. 


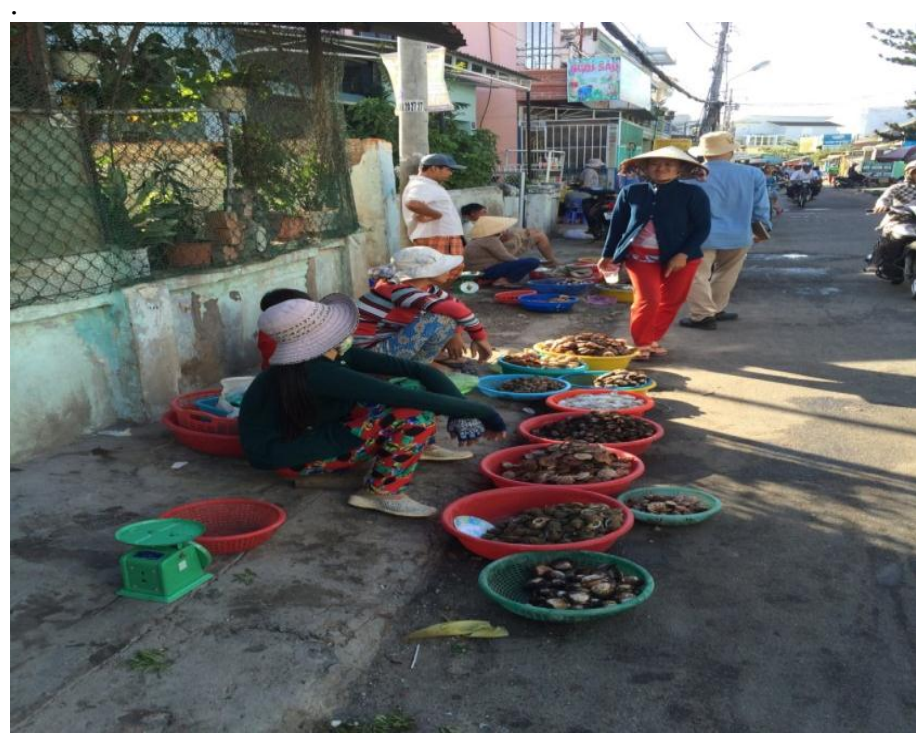

Figure 14 Local residents sell part of their catch in the roads adjacent to their houses in Phu Trinh

\section{Conclusions}

The present work has highlighted the high vulnerability of one particular settlement within the larger Phan Thiet city in Vietnam, inhabited by comparatively poorer members of the community, mostly engaged in the fishing sector. The settlement lies only 49 centimetres above mean water level, and would likely be completely washed out by any significant flooding event, requiring residents to swiftly evacuate or risk losing. However, although local inhabitants appear to have a moderate to high level of awareness about flooding hazards, the evaluation of the risk that these pose to them is moderate to low. This can be attributed to the short time that the area has been inhabited, the relative young age of its population and a long time since the last major flooding took place in the area.

The evaluation by the community seems to indicate that they perceive flooding to be a low or moderate risk. However, despite the low frequency of these events, given their high vulnerability, even moderate flooding could complete destroy the community. Thus, it is imperative for local authorities to take some form of action to improve the resilience of this community. Local authorities are planning to build a dyke along the river banks and relocate this community, though when this will take place is currently uncertain. In the meantime, it is crucial to increase the awareness of the local community regarding disasters, which could take the form of frequent evacuation exercises, and the placement of some form of flooding awareness sign that would indicate how people should evacuate in the event of a flooding risk.

\section{Acknowledgements}

This work was made possible thanks to the AUN/SEED-Net Collaborative Research Program for Common Regional Issues (CRC) through the research project "Coastal disasters and climate change in Southeast Asia: An assessment and countermeasures for sustainable development of the fast-growing coastal areas" (Project No. HCMUT CRC 1501 and 1601) and JSPS KAKENHI (16KKo121). The authors would also like to acknowledge support from the Graduate Program in Sustainability, Global Leadership Initiative (GPSS-GLI), funded by the Japanese Ministry of Education.

\section{References}

[1] Takagi H., Thao N.D., Esteban M. (2014) Tropical Cyclones and Storm Surges in Southern Vietnam, IN: Thao N.D., Takagi H., Esteban M. (eds.) Coastal Disasters and Climate Change in Vietnam: Engineering and Planning Perspectives 1st ed., Elsevier, pp.3-16.

[2] Anh L. T., Takagi H., Thao N. D., Esteban M. (2017) Investigation of Awareness of Typhoon and Storm Surge in the Mekong Delta - Recollection of 1997 Typhoon Linda, Journal of Japan Society of Civil Engineers, Ser. B3 (Ocean Engineering), Vol. 73 (2)

[3] Shibayama, T. (2015) 2004 Indian Ocean Tsunami, in Handbook of Coastal Disaster Mitigation for Engineers and Planners. Esteban, M., Takagi, H. and Shibayama, T. (eds.). Elsevier, Amsterdam

[4] Tasnim K. M., Shibayama T., Esteban M., Takagi H., Ohira K., Nakamura R. (2014) Field observation and numerical simulation of past and future storm surges in the Bay of Bengal: case study of cyclone Nargis, Natural Hazards, p. 29., DOI: 10.1007/s11069-014-1387-x

[5] Mikami, T., and Shibayama, T., (2015a) Tsunami Disasters in Remote Island: 2009 Samoan and 2010 Mentawai Island Tsunamis, in Handbook of Coastal Disaster Mitigation for Engineers and Planners. Esteban, M., Takagi, H. and Shibayama, T. (eds.). Elsevier, Amsterdam

[6] Aranguiz, R., (2015) Tsunami Resonance in the Bay of Concepcion (chile) and the Effect of Future Events. in Handbook of Coastal Disaster Mitigation for Engineers and Planners. Esteban, M., Takagi, H. and Shibayama, T. (eds.). Elsevier, Amsterdam

[7] Esteban, M., Tsimopoulou, V., Mikami, T., Yun, N. Y., Suppasri, A. and Shibayama, T. (2013) "Recent Tsunami Events and Preparedness: Development of Tsunami Awareness in Indonesia, Chile and Japan", Journal of Disaster Risk Reduction, pp. 84-97

[8] Mori, N., Takahashi T. and The 2011 Tohoku Earthquake Tsunami Joint Survey Group (2012) "Nationwide survey of the 2011 Tohoku earthquake tsunami”, Coastal Engineering Journal, Vol.54, Issue 1, pp.1-27.

[9] Mikami, T., Shibayama, T., Esteban, M. and Matsumaru, R., (2012) "Field Survey of the 2011 Tohoku Earthquake and Tsunami in Miyagi and Fukushima Prefectures", Coastal Engineering Journal (CEJ), Vol. 54, No. 1, pp. 1-26

[1o] Mikami, T., Shibayama, T., Takagi, H., Matsumaru, R., Esteban, M., Thao, N.D., De Leon, M., Valenzuela, V. P., Oyama, T., Nakamura, R., Kumagai, K. and Li, S. (2016) "Storm Surge Heights and Damage Caused by the 2013 Typhoon Haiyan along the Leyte Gulf Coast", Coastal Engineering Journal. Vol. 58 No. 1

[11] Takagi, H. and Esteban, M. (2016) "Statistics of Tropical Cyclone Landfalls in the Philippines -Unusual Characteristics of 2013 Typhoon Haiyan", Natural Hazards, 8o(1), pp. 211-222. DOI: 10.1007/s11069-015-1965-6

[12] Suppasri, A., Abe, Y., Yasuda, M., Fukutani, Y. and Imamura, F. (2015) Tsunami Signs, Memorials and Evacuation Drills in Miyagi Prefecture after the 2011 Great East Japan Tsunami, in Handbook of Coastal Disaster Mitigation for Engineers and Planners. Esteban, M., Takagi, H. and Shibayama, T. (eds.). Elsevier

[13] Esteban, M., Valenzuela, V. P., Matsumaru, R., Mikami, T., Shibayama, T., Takagi, H., Thao, N.D., De Leon, M. (2015a) "Storm Surge Awareness in the Philippines Prior to Typhoon Haiyan: a Comparative Analysis with Tsunami Awareness in Recent Times", Coastal Engineering Journal Vol. 58 No. 1

[14] Esteban, M., Valenzuela, V. V. Namyi, Y., Mikami, T., Shibayama, T., Matsumaru, R., Takagi, H. Thao, N.D., de Leon M., , Oyama, T. Nakamura, R. (2015b) "Typhoon Haiyan 2013 Evacuation Preparations and Awareness"., J-SustaiN 3 (1) 37-45

[15] Takagi H., Esteban M., Tam T.T. (2014a) Coastal Vulnerabilities 
in a Fast-Growing Vietnamese City, IN: Thao N.D., Takagi H., Esteban M. (eds.) Coastal Disasters and Climate Change in Vietnam: Engineering and Planning Perspectives ist ed., Elsevier, Pages 157-171

[16] Hung N. M., Larson M. (2014) Coastline and River Mouth Evolution in the Central Part of the Red River Delta, IN: Thao N.D., Takagi H., Esteban M. (eds.) Coastal Disasters and Climate Change in Southern Vietnam, Engineering and Planning Perspectives 1st ed., Elsevier Pages 233-255

[17] Cong L.V., Cu N.V., Shibayama T. (2014) Assessment of Vietnam Coastal Erosion and Relevant Laws and Policies, IN: Thao N.D. Takagi H., Esteban M. (eds.) Coastal Disasters and Climate Change in Vietnam: Engineering and Planning Perspectives 1st ed., Elsevier, Pages 81-106.

[18] Larson M., Hung N.M., Hanson H., Sundström A., Södervall E. (2014) Impacts of Typhoons on the Vietnamese Coastline: A Case Study of Hai Hau Beach and Ly Hoa Beach, IN: Thao N.D., Takagi H., Esteban M. (eds.) Coastal Disasters and Climate Change in Vietnam: Engineering and Planning Perspectives 1st ed., Elsevier, Pages 17-42

[19] Ca V.T., Xuyen N.D. (2008). Tsunami risk along Vietnamese coast. Journal of Water Resources and Environmental Engineering, Water Resources University, No. 23, 24-33.

[20] Thao N.D. (2015) Evaluation of tsunami hazards along the Vietnamese coast, Journal of Science and Technology, Vol. 53 (5A), pp. 220-227

[21] Ca V.T. (2014) Tsunami Hazard in Vietnam, IN: Thao N.D., Takagi H., Esteban M. (eds.) Coastal Disasters and Climate Change in Vietnam: Engineering and Planning Perspectives ist ed., Elsevier, Pages 277-302

[22] Oka, E. A., Synolakis, C. E., \& Kalligeris, N. (2011). Tsunami simulations for regional sources in the South China and adjoining seas. Pure and Applied Geophysics, 168, 1153-1173.

[23] Mikami T., Takabatake T. (2014) Evaluating Tsunami Risk and Vulnerability Along the Vietnamese Coast, IN: Thao N.D., Takagi H., Esteban M. (eds.) Coastal Disasters and Climate Change in Vietnam: Engineering and Planning Perspectives 1st ed., Elsevier, Pages 303-319

[24] Leelawat, N, Mateo, C. M. R., Gaspay, S. M., Suppasri, A., Imamura, F. (2014) Filipinos "Views on the Disaster Information for the 2013 Super Typhoon Haiyan in the Philippines", International Journal of Sustainable Future for Human Security, J-SustaiN. Vol. 2 No. 2 pp. 61-73.

[25] Lindell, M. K. and Prater, C. S. (2010) Tsunami Preparednes on the Pregon and Wshington Coast: Recommendations for Research. Natural Hazards Review, pp 69-81

[26] Whitehead, J. C., Edwards, B., Van Willigen, M., Maiolo, J. R., Wilson, K., \& Smith, K. T. (200o). Heading for higher ground: factors affecting real and hypothetical hurricane evacuation behavior. Global Environmental Change Part B: Environmental Hazards, 2(4), 133-142.

[27] Gray-Graves, A., Turner, K. W., \& Swan, J. H. (2010). Sustainability of seniors: Disaster risk reduction management. The Journal of Aging in Emerging Economies, 2(2), 64-78

[28] Fraser, S. A., Leonard, G., S and Johnston, D., M. (2013) Intended Evacuation Behaviour in a Local Earthquake and Tsunami at Napier, New Zealand, GNS Science Report 2013/26, $55 \mathrm{pp}$.

[29] Matsumaru, R. and Kawaguchi. R. (2015), "Awareness on Tsunami Disaster of Visitors - Case of Enoshima, Katase and Kugenuma Area in Kanagawa, Japan", Proceedings for JSCE (Japan Society of Civil Engineers) 2015 Annual Meeting (DVDROM), IV-o44 (p87 - p88), JSCE, September 2015.

[30] San Carlos-Arce, R., Onuki, M., Esteban, M. and Shibayama, T. (2017) "Risk Awareness and Intended Tsunami Evacuation Behaviour of International Tourists in Kamakura City, Japan". International Journal of Disaster Risk Reduction 23, 178-192.

[31] Takabatake, T., Shibayama, T., Esteban, M., Ishii, H. and Hamano, G. (2017) "Simulated Tsunami Evacuation Behaviour of Local Residents and Visitors in Kamakura, Japan”. International Journal of Disaster Risk Reduction 23, 1-14

[32] Kanhai, L. D. K., Singh, D, Lauckner, B., Ebi, K. L. and Chadee, D. (2016) Knowledge, attitude and practices of coastal communities in Trinidad and Tobago about tsunamis, Natural Hazards. DOI 10.10007/s11069-015-2138-3

[33] Esteban M., Thao N.D., Takagi H., Valenzuela P., Tam T.T, Trang D.D.T, Anh L.T. (2014) Storm Surge and Tsunami Awareness and Preparedness in Central Vietnam,IN: Thao N.D., Takagi H., Esteban M. (eds.) Coastal Disasters and Climate Change in Vietnam: Engineering and Planning Perspectives ist ed., Elsevier, Pages 321-336

[34] Yun, N. Y., Hamada, M. (2014) Evacuation behavior and fatality during the 2011 Tohoku Tsunami. Science of Tsunami Hazards, 33 (3): 144-155

[35] Lindell, M. K., Prater, C. S., Gregg, C. E., Apatu, E. J. I, Huang, S.K. and $\mathrm{Wu}, \mathrm{H}$. C. (2015) Households' immediate responses to the 2009 American Samoa Earthquake and Tsunami. International Journal of Disaster Risk Reduction, 12:328-340.

[36] Hu, M., Takara, K., Duan, W., He, B., and Luo, P. (2015), Integrated Assessment of Hydro-Climatology Variability in Kamo River Basin: Confronting Climate and Extremes, JSustain, (3) pp. 46-55

[37] Le Banc, D., Freire, C., Jussila, R., Vaturi, T. Chapter 2: The infrastructure - inequality - resilience nexus. Global Sustainable Development Report, 2016.

[38] UNISDR (United Nations International Strategy for Disaster Reduction) (2015). Sendai framework for disaster risk reduction 2015-2030. Retrieved May 20, 2017, from http://www.preventionweb.net/files/43291_sendaiframeworkfor drren.pdf

[39]National Water Plan of the Netherlands, http://english.verkeerenwaterstaat.nl/english/Images/NWP\%2 oenglish_tcm249-274704.pdf. Accessed 10 August 2012

[40] Tsimopoulou, V., Vrijling, J.K., Kok, M., Jonkman, S.N., Stijnen, J.W., (2013) Economic implications of multi-layer safety projects for flood protection, Proc. ESREL conference, Amsterdam

[41] Ong, J. M., Jamero, M. L., Esteban, M., Honda, R. and Onuki, M. (2016) "Challenges in Build-Back-Better Housings Reconstructions Programs for Coastal Disaster Management: Case of Tacloban City, Philippines", Coastal Engineering Journal. Vol. 58 No. 1

[42] Jamero, L., Onuki, M. and Esteban, M., Billones-Sensano, X. K., Tan, N., Nellas, A., Takagi, H., Thao, N. D. and Valenzuela, V. P. (2017) "Small island communities in the Philippines prefer local measures to relocation in response to sea-level rise", Nature Climate Change 7, 581-586

[43] Jamero, L., Esteban., M. and Onuki, M. (2016) "Potential InSitu Adaptation Strategies for Climate-Related Sea-Level Rise: Insights from a Small Island in The Philippines Experiencing Earthquake-Induced Land Subsidence", J-SustaiN 4 (2) pp 